\title{
Development and Testing of a High-Average Power, 94-GHz Gyroklystron
}

Bruce G. Danly, Member, IEEE, Monica Blank, J. P. Calame, Member, IEEE, Baruch Levush, Senior Member, IEEE, Khanh T. Nguyen, Dean E. Pershing, R. K. Parker, Fellow, IEEE, Kevin L. Felch, Member, IEEE, B. G. James, P. Borchard, P. Cahalan, T. S. Chu, H. R. Jory, Life Fellow, IEEE, Thomas A. Hargreaves, Member, IEEE, Richard B. True, Fellow, IEEE, Wes G. Lawson, Senior Member, IEEE, and Thomas M. Antonsen, Jr., Member, IEEE

\begin{abstract}
The development of a $10-\mathrm{kW}$ average power, 94-GHz gyroklystron amplifier is described. This average power was obtained with $11 \%$ radio frequency (RF) duty factor and 92-kW peak power in the $\mathrm{TE}_{01}$ circular cavity mode. The instantaneous bandwidth was $420 \mathrm{MHz}$, and the efficiency was $33.5 \%$. Low-duty-factor testing also yielded a peak power of as much as $115 \mathrm{~kW}$ with $600-\mathrm{MHz}$ instantaneous bandwidth. This development effort was carried out over the past three years and represents record average power performance in an amplifier at this frequency.
\end{abstract}

Index Terms-Amplifier, gyro-klystron, gyrotron, millimeter wave, W-band.

\section{INTRODUCTION}

$\mathbf{T}$ HE development of gyrotron oscillators and amplifiers has been ongoing for more than three decades as a result of their unsurpassed capability in delivering high power at millimeter-wave frequencies [1], [2]. Gyrotron oscillators have found wide usage in such diverse applications as electron cyclotron resonance heating (ECRH) of fusion plasmas [3], industrial processing of ceramics [4], and dynamic nuclear polarization in conjunction with nuclear magnetic resonance (NMR) imaging [5].

Although the predominant emphasis of the gyrotron development community worldwide has been toward the development of gyrotron oscillators, gyrotron amplifiers have also received attention. This attention is the result of their potential as

Manuscript received October 19, 1999; revised March 9, 2000. This work was supported by the Office of Naval Research.

B. G. Danly, J. P. Calame, B. Levush, and R. K. Parker are with the Vacuum Electronics Branch, Electronics Science and Technology Division, Naval Research Laboratory, Washington, DC 20375 USA (e-mail: danly @ nrl.navy.mil)

M. Blank is with the Vacuum Electronics Branch, Electronics Science and Technology Division, Naval Research Laboratory, Washington, DC 20375 USA She is now with Communications and Power Industries, Palo Alto, CA 94304 USA.

K. T. Nyugen is with the Vacuum Electronics Branch, Electronics Science and Technology Division, Naval Research Laboratory, Washington, DC 20375 USA, and with KN Research, Silver Spring, MD 20905 USA.

D. E. Pershing is with the Vacuum Electronics Branch, Electronics Science and Technology Division, Naval Research Laboratory, Washington, DC 20375 USA, and with the Mission Research Corporation, Newington, VA 22122 USA.

K. L. Felch, B. G. James, P. Borchard, P. Cahalan, T. S. Chu, and H. R. Jory are with the Microwave Power Products Division, Communications and Power Industries, Palo Alto, CA 94304 USA.

T. A. Hargreaves and R. B. True are with the Electron Devices Division, Litton Industries, Inc., San Carlos, CA 94070 USA.

W. G. Lawson and T. M. Antonsen, Jr., are with the Institute for Plasma Research, University of Maryland, College Park, MD 20742 USA.

Publisher Item Identifier S 0093-3813(00)05700-3. radio frequency (RF) drivers for linear colliders [6] and their application to high-power millimeter-wave radar. A variety of radar applications require the development of high-power millimeter-wave amplifiers such as gyroklystrons. Precision tracking of targets is often best accomplished with high-frequency radars [7]. The imaging of space objects, such as missiles, asteroids, space debris, and satellites, also requires the use of high-power millimeter-wave radars [8]-[13]. These radar applications have resulted in continuing interest in gyrotron amplifiers, including their many variants, such as the gyroklystron, gyrotwystron, and gyro-traveling wave tube (TWT). Of the many types of gyro-amplifiers that have been investigated in experimental low-average power devices, the most common type usually considered for radar application is the gyroklystron [14], [15].

Both this general need for millimeter-wave amplifiers for radar and the specific need of an amplifier for a planned Naval Research Laboratory (NRL) millimeter-wave radar have led to the development, over the past several years, of a high average power $94-\mathrm{GHz}$ gyroklystron amplifier by a combined government, industry, and academic team [16]. It is the results of this team effort, reported on briefly in [16], that are described in detail in this paper. The paper is organized as follows. The issues addressed during the design procedure and the design are described in Section II, followed by presentation in Section III of the experimental test results. The experimental results are then discussed and compared with numerical codes in Section IV. Improvements to the codes that resulted from this careful comparison with experimental data are described. Finally, planned future directions and conclusions are presented in Section V.

\section{GYROKLYSTRON DESIGN}

The design of the gyroklystron amplifier was a major effort from both the physics and engineering points of view. The design procedure involved the use of many theoretical models and computer codes. These models and codes have been benchmarked over the past several years by a successful series of experimental low-duty-factor gyroklystron devices of narrow bandwidth at the University of Maryland, and of higher bandwidth at NRL [17]-[19]. Central to the suite of design codes are those codes that model the details of the beam-wave interaction in the gyroklystron circuit. There are two principal codes for this modeling activity, MAGYKL [20] (colloquially 
pronounced "magical") and MAGY ("maggie"). The interaction circuit was designed primarily using a time-dependent version of the nonlinear code MAGYKL [17]. In this formalism, the cold-cavity RF electromagnetic fields are determined by a scattering matrix method [21], and then these fields are used for the integration of particle orbits within the circuit. The field amplitudes are self-consistently adjusted to represent the actual power transfer from the beam to the wave and thus achieve energy balance. However, the model for the fields in this code does not include modification of the longitudinal field profile in the cavities by the beam electric susceptibility, and in this sense, this code is not self-consistent. The fully self-consistent (in this sense) analysis code is MAGY [22], which was used primarily in the analysis of the experimental results reported herein, rather than in the original design of the device. Several other auxiliary interaction codes were also employed for particularly specialized computational tasks, including a linear theory analysis code, QPB [23], which was used to determine the stability of each cavity and drift section for the nominal operating parameters, and drift tube stability codes, as described below. A more detailed description of the theoretical tools and design methodology can be found in [24].

The electron gun design for this gyroklystron was of critical importance to the success of the development effort. The electron beam is formed by a $65-\mathrm{kV}, 6-\mathrm{A}$ magnetron injection gun that was designed to have very good beam quality, with perpendicular rms velocity spreads near $2 \%$ [25]. The electron gun was designed with a double anode configuration, namely, with a modulating anode (mod-anode) and an anode nominally at ground potential. The mod-anode is referenced to cathode potential, and beam cutoff condition may be achieved with a $-2.5-\mathrm{kV}$ mod-anode bias. The beam $\alpha$ is controlled by the voltage on the modulating anode (pulse-top voltage), which is nominally $17 \mathrm{kV}$ above cathode potential, and by the superconducting coil that controls the magnetic field over the cathode.

The RF design goal for this gyroklystron development was $80-\mathrm{kW}$ peak power at $12.5 \%$ duty factor for an average power of $10 \mathrm{~kW}$. In addition, a goal of $600-\mathrm{MHz}$ bandwidth $(3 \mathrm{~dB})$ at 94-GHz center frequency was the objective. A four-cavity circuit operating with circular $\mathrm{TE}_{011}$ cavity modes was chosen for the design. The circuit consists of a drive cavity (cavity 1), two bunching (idler) cavities (cavities 2 and 3), and an output cavity (cavity 4), all designed to operate in this mode at the fundamental of the cyclotron resonance. To determine the optimal circuit parameters, an extensive study was made of the tradeoffs in gain, power, and bandwidth that come through varying cavity and beam parameters. A complete description of this design study can be found in [26] and is, thus, not repeated here. For the optimized circuit parameters detailed in Table I, the predicted efficiency and peak output power versus frequency for a $65-\mathrm{kV}$, 6-A electron beam are shown in Fig. 1. As shown in the figure, efficiencies of up to $25 \%$ and bandwidths of approximately 600 $\mathrm{MHz}$ are expected for beam velocity ratios, $\alpha=v_{\perp} / v_{z}$, between $\alpha=1.5$ and $\alpha=1.7$ and an rms perpendicular velocity spread of $2.2 \%$. The output power and efficiency are sensitive to relatively small changes in the beam velocity ratio.

Following the output cavity is a nonlinear up-taper to the collector, which also serves as the output waveguide. The shape of
TABLE I

Design and Measured Values of CAVITy PaRAMETERS For FouR-CAVITY GYROKLYSTRON AMPLIFIER CIRCUIT. THE COLD-TeST VALUE FOR CAVITY 1 WAS MEASURED FROM REFLECTION THROUGH THE DRIVE PORT AFTER FINAL ASSEMBLY

\begin{tabular}{lccccc}
\hline & & Design & \multicolumn{3}{c}{ Cold Test } \\
\hline & $\mathrm{L}(\mathrm{cm})$ & $\mathfrak{f}_{0}(\mathrm{GHz})$ & $\mathrm{Q}_{\mathrm{L}}$ & $\mathfrak{f}_{0 \text { vac }}$ & $\mathrm{Q}_{\mathrm{L}}$ \\
& & & & $(\mathrm{GHz})$ & \\
\hline cavity 1 & 0.36 & 93.41 & 126 & 93.25 & 130 \\
cavity 2 & 0.48 & 94.21 & 175 & 94.24 & 175 \\
cavity 3 & 0.48 & 93.28 & 175 & 92.82 & 175 \\
cavity 4 & 0.87 & 93.89 & 162 & 93.67 & 160 \\
\hline
\end{tabular}

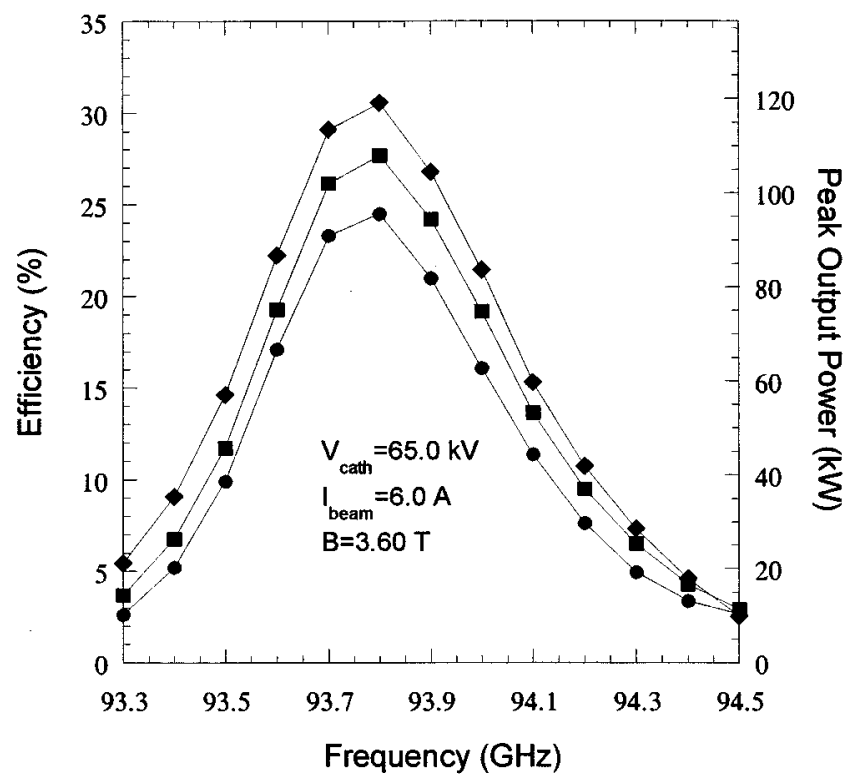

Fig. 1. Theoretical prediction for peak output power and efficiency versus drive frequency for the four cavity gyroklystron amplifier detailed in Table I for beam velocity ratios $\alpha=1.5$ (filled circles), $\alpha=1.6$ (filled squares), and $\alpha=1.7$ (filled diamonds).

the taper was specially designed to minimize mode conversion while tapering up to a large radius in a short length [27]. The power is coupled out of the device through a chemical vapor deposition (CVD) diamond window, and the output mode is $\mathrm{TE}_{01}$, which propagates in $1.284^{\prime \prime}$ OD circular waveguide. Cold tests showed that for frequencies in the range of $93 \mathrm{GHz}$ to $95 \mathrm{GHz}$, between $0.25 \%$ and $1 \%$ of the power incident on the window is reflected.

\section{A. Cavity Electromechanical Design}

From performance calculations with smooth wall cavities using the aforementioned design codes, the design cavity parameters are given in Table I. For optimum gyroklystron performance, the primary design requirement for all cavities is operation at the desired resonant frequency $f_{r}$ and bandwidth or $Q$. The input coupler has to satisfy the following additional requirements. The $\mathrm{TE}_{011}$-mode should be excited with high mode purity and maximum power coupling. The input coupler design chosen was one in which the input waveguide excites 
the $\mathrm{TE}_{411}$-mode in an outer coaxial cavity, and power is then coupled through four axial slots into the inner cylindrical cavity $\mathrm{TE}_{011}$-mode. This type of input cavity design has been previously described [24], [28]. This input coupler was designed using both HFSS, a three-dimensional (3-D) finite-element electromagnetics code [29] and ARGUS, a 3-D finite-difference electromagnetics code [30]. The differing situations in which these two complementary codes were used in the design effort has been previously described [24].

For the operation of the amplifier at the full designed RF duty factor $(12.5 \%)$, the drive-frequency-dependent average power load in the bunching cavities has a worst-case value of $400 \mathrm{~W}$. Ohmic loading by itself is of course insufficient to achieve a loaded $Q$ of 175 . Furthermore, loading by the addition of ceramic rings internal to the cavities, which has been employed in low-duty-factor experimental devices at NRL and elsewhere, is too difficult to cool adequately at these high average power levels. Therefore, to meet this average power requirement for the operating mode, power is extracted from the bunching cavities to external loads. This yields a total cavity $Q$ that is dominated by the external (or diffractive) $Q$-factor of these loads, and the heat load is dissipated externally.

After the design of the bunching cavities was finalized for the $\mathrm{TE}_{011}$ operating mode resonant frequency and $Q$-factor, the $Q$-factor of the cavities in other potentially competing modes $\left(\mathrm{TE}_{012}, \mathrm{TE}_{112}\right.$, and $\left.\mathrm{TE}_{212}\right)$ was also calculated and checked against the starting $Q$-factor of these modes. The starting $Q$-factor for a given parasitic mode is that $Q$ that would cause the oscillation threshold in that mode to be reached at the design beam current. The loading schemes employed to achieve the requisite frequency and $Q$ in the operating mode must in addition have $Q$-factors for the parasitic modes that are below the start- $Q$ of those modes. The parasitic modes checked were the $\mathrm{TE}_{012^{-}}$and $\mathrm{TE}_{212}$-modes, with starting $Q$-factors of 800 and 425 and frequencies of $104.3 \mathrm{GHz}$ and $88.9 \mathrm{GHz}$, respectively. The designed bunching cavities had a calculated $Q$ of 192 and 68 in these modes, respectively, according to HFSS simulations. The electromagnetics code ARGUS [30] was also used in the design. ARGUS simulations yielded calculated $Q$-factors of 154 and 66, respectively, in excellent agreement with the HFSS calculations. Consequently, the cavity design was believed to be stable to oscillations in these parasitic modes. Finally, the stabilization of the $\mathrm{TE}_{112}$-mode was left to the drift-tube loading scheme (see below).

\section{B. Dielectric Probe Design and Cavity Testing}

Even before beginning fabrication of the cavities, it was recognized that cold-test capability would be critical to the development of the proper fabrication procedure given the finalized cavity designs. The stagger tuning of the existing design would admit some variation in actual fabricated cavity resonant frequency and $Q$ without significant loss of device performance (indeed, the design was optimized for a certain degree of insensitivity to exact frequencies and $Q$ ). However, the degree of cavity sensitivity to machined cavity diameter [118 MHz for a $5 \mu \mathrm{m}\left(0.0002^{\prime \prime}\right)$ change in diameter] necessitated the development of an accurate and precise cold-test procedure for quality control of fabricated cavities at each step of the assembly

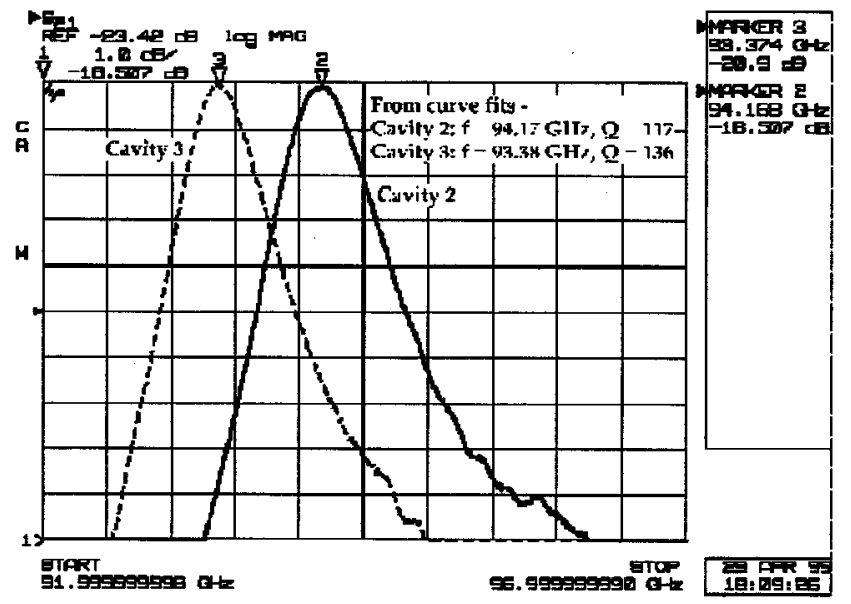

Fig. 2. Network Analyzer transmission response curves for cavities 2 and 3, showing quality of response.

process. Space considerations precluded the usage of apertures in the cavities specifically for cold-test purposes. It was therefore decided to rely on $\mathrm{TE}_{01}$ axial transmission that was evanescently coupled through cavity irises to determine the cavity resonant frequency and $Q$. This required the use of a high dynamic range W-band network analyzer and additional RF test equipment as follows. Marie converters were used to convert from the $\mathrm{TE}_{10}$-mode in WR-10 rectangular waveguide to the $\mathrm{TE}_{01}$-mode in $0.2^{\prime \prime}$ diameter circular guide. To allow propagation of the $\mathrm{TE}_{01}$-mode in waveguide diameters below air-loaded cutoff, diagnostic probes were fabricated using a dielectric-loaded circular waveguide with approximately the same diameter as the cavity iris. Each waveguide was connected to a nonlinear transition region to couple a $\mathrm{TE}_{01}$ wave in $0.2^{\prime \prime}$ air loaded waveguide to a $\mathrm{TE}_{01}$ wave in $0.109^{\prime \prime}$ diameter Rexolite-loaded waveguide with minimal reflection and mode conversion [31].

Key issues that were addressed by the probe design were precision manufacture and the minimization of reflections in the transmission chain. At the small dimensions required for W-band operation, the return loss of the transition region is sensitive to the actual taper profiles, as well as the relative axial position of the wall and dielectric tapers. Tight tolerances are also required to permit "threading" of the probes through the brazed cavity stack. In addition, transmission profiles were found to be sensitive to small mismatches $(\sim 25 \mathrm{~dB})$ in the transmission chain. With precision manufacture of the dielectric probes, careful alignment, $\mathrm{TE}_{11^{-}}$and $\mathrm{TE}_{21}$-mode filters, and Thru-Reflect-Line (TRL) calibration [32], [33] at the probe tips to minimize mismatch effects, consistent and reliable results have been obtained.

Resonant frequency measurements are found to be repeatable to within $\sim 40 \mathrm{MHz}$ (better than $0.05 \%$ ). $Q$ measurements exhibit more variation, $Q_{T}$, typically, $\sim 150 \pm 20$. Finally, the resonant frequencies measured using dielectric probes are generally within $50 \mathrm{MHz}$ of frequencies measured with other methods, such as by transmission measurement through coupling holes in $\mathrm{TE}_{011}$-mode test cavities used in NRL low-duty-factor experiments. Sample data for "circuit-ready" cavities are shown in Fig. 2. As a further indication of the accuracy possible using dielectric probes, Fig. 3 shows the measured and calculated char- 


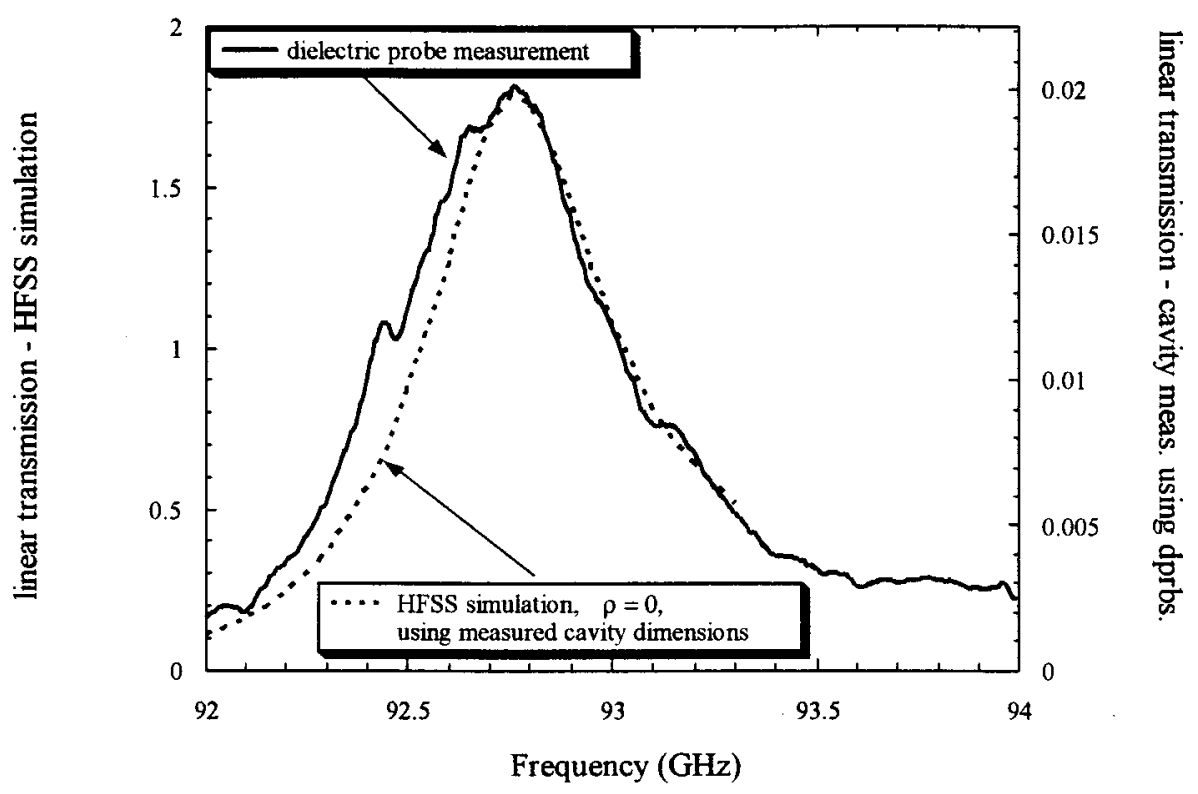

Fig. 3. Comparison of cavity transmission cold-test using dielectric probe and simulation of the same cavity using measured dimensions with HFSS electromagnetics code.

acteristics of an intermediate cavity. For the HFSS calculation, the measured mechanical cavity dimensions were used. Resistive wall losses were not included in this simulation.

\section{Drift Tube Design}

A critical issue in the design of the drift tubes is maintaining stability to spurious electromagnetic oscillations. Although the drift tube radius is deliberately made small enough to prevent $\mathrm{TE}_{01}$-mode propagation at the operating frequency, parasitic oscillations can occur by one of two mechanisms. First, the radial wall transitions between the drift tube and the gyroklystron cavities on either side can create reflections, allowing the drift tube to act as an inadvertent resonant cavity to higher frequency modes. In the second mechanism, lower order modes, such as the $\mathrm{TE}_{11}$ and $\mathrm{TE}_{21}$, which can propagate at frequencies considerably below the $\mathrm{TE}_{01}$ cutoff, can exhibit gyro-backward-wave instabilities. In order to achieve stability for both of these possible instability mechanisms, lossy-dielectric-lined drift tubes were employed.

Of the various arrangements of lossy dielectrics in the drift tubes that have been described in the literature [34], we decided to employ the structure of Fig. 4 because it is simple and highly effective [35]. This arrangement has been described previously [24].

The detailed design procedure is beyond the scope of the present paper; however, a short summary follows. The basic design process can be broken into three steps [24]. The first step is a study of the stability of a simple cylindrical drift tube without lossy dielectric, in which the troublesome modes are identified, the likely oscillation frequencies are computed, and the conditions for starting oscillation are examined. For a cavity-like oscillation, a maximum stable $Q$ can be determined through a linear start oscillation computation with test particles (in the same manner as was carried out for the cavities) [20], and for gyro-backward-wave oscillations, a critical length and growth

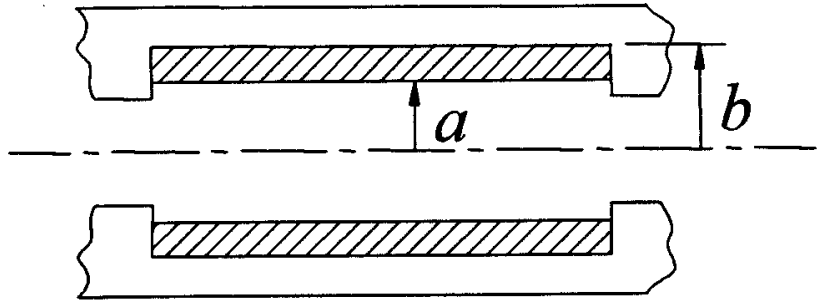

Fig. 4. Diagram of the drift tube geometry. The dielectric is shown by the hatched area.

rate can be computed with Vlasov theory [36]. The second step consists of selecting a suitable ceramic material for use as the lossy dielectric, and either determining the complex dielectric constant experimentally or relying on published values. The third step consists of modeling the dielectrically lined drift tube using an infinite-length, dielectrically loaded waveguide analysis to compute the modified dispersion curves, the attenuations per unit length, the modified oscillation frequencies, and the approximate quality factors of a finite length section of drift tube (if the ends were perfectly reflecting). The radial thickness of the dielectric is selected by repeating step three for a variety of dielectric thicknesses in an iterative fashion until acceptable values of attenuation and quality factor are achieved.

An instability in a drift tube occurs at a frequency near the intersection between the dispersion curve (a plot of frequency versus axial wavenumber) of an electromagnetic wave in the drift structure and the dispersion line for Doppler upshifted cyclotron waves supported by the electron beam. For the nominal gyroklystron operating point of $65-\mathrm{kV}$ beam voltage with $36.8-\mathrm{kG}$ magnetic field and a velocity ratio of 1.5 , and using a slightly enlarged drift tube radius of $1.75 \mathrm{~mm}$, analysis of the relevant dispersion curves indicates that a potential $\mathrm{TE}_{11}$ backward-wave oscillation exists at about $76.7 \mathrm{GHz}$ and a $\mathrm{TE}_{11}$ cavity oscillation could occur near $119 \mathrm{GHz}$. Start-oscillation 


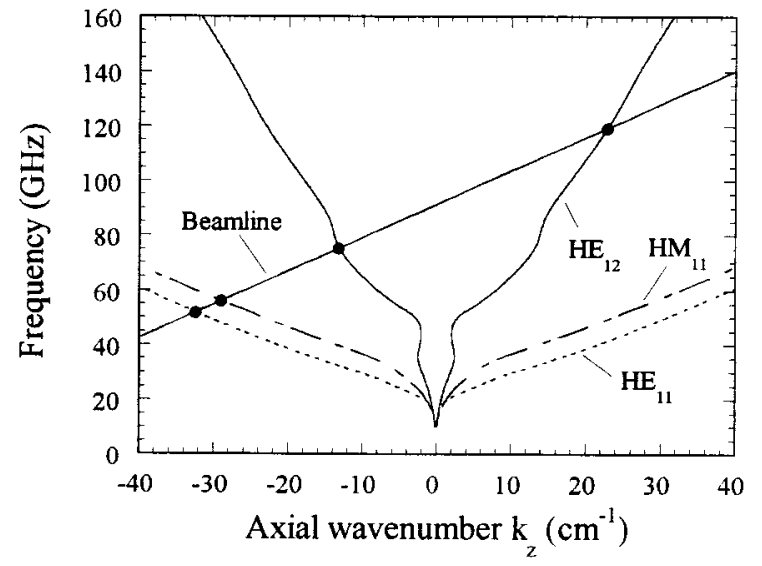

Fig. 5. Dispersion diagram of hybrid modes with an azimuthal number of 1 , for a drift tube loaded with $\varepsilon *=12-j 3.7$ dielectric having an inner radius of $1.75 \mathrm{~mm}$ and a radial dielectric thickness of $0.8 \mathrm{~mm}$. The beam line for the nominal operating point is also shown, and circles indicate possible oscillation frequencies.

analysis at a beam current of 6 A shows that the critical quality factor for the higher frequency oscillation is about 200, and the backward-wave growth rate of the low frequency oscillation is $14 \mathrm{~dB} / \mathrm{cm}$. A composite ceramic composed of $80 \% \mathrm{BeO}$ and $20 \%$ SiC by weight was selected as the dielectric loading material. The complex dielectric constant at $94 \mathrm{GHz}$ is about $12-j 3.7$.

For good attenuation, the radial thickness of dielectric liner should be an odd number of quarter wavelengths at the frequency of concern. For an oscillation at $76.7 \mathrm{GHz}$, a quarter wavelength in the lossy dielectric is about $0.27 \mathrm{~mm}$, but this is too thin to be practical; so a dielectric thickness near threequarter wavelength $(\sim 0.8 \mathrm{~mm})$ is a better choice. To analyze the stability, the vacuum dispersion relation is replaced by the dispersion equation for waves in a dielectrically lined pipe [37]. This dispersion relation is a function of $a, b, k_{z}, \varepsilon *$, and $n$, where $\varepsilon *$ is the complex dielectric constant of the dielectric liner, $a$ is the inner radius of the dielectric, $b$ is the outer radius of the dielectric (assumed to be enclosed by metal beyond $r=b$ ), and $n$ is the azimuthal mode number. The dispersion relation must be solved numerically for the $k_{z}$ versus $\omega$ relationship to compute the intersections with the beam cyclotron dispersion. The infinitely long model is appropriate when the physical length of the drift tube is much longer than is the guide wavelength $2 \pi / k_{z}$.

For a radial thickness $b-a$ of $0.8 \mathrm{~mm}$, and retaining $a=1.75$ $\mathrm{mm}$, we obtain the dispersion diagrams shown in Fig. 5. Only the modes with an azimuthal number of unity are shown here, because for this system, all other azimuthal modes were found to be more stable. Potential oscillation frequencies are indicated by circles in the figure, and they consist of backward waves near 52, 56, and $76 \mathrm{GHz}$, and a forward wave at $119 \mathrm{GHz}$. The first two intersections are related to the original $\mathrm{TE}_{11}$ and $\mathrm{TM}_{11}$ dielectric-free solutions that have been almost completely drawn into the dielectric (to become hybrid $\mathrm{HE}_{11}$ - and $\mathrm{HM}_{11}$-modes). (The $\mathrm{HE}_{11}$ - and $\mathrm{HM}_{11}$-modes are sometimes also referred to as $\mathrm{HE}_{11}$ - and $\mathrm{EH}_{11}$-modes in the literature). These solutions are heavily damped by the dielectric, with attenuations reaching 50 $\mathrm{dB} / \mathrm{cm}$ in the $50-60-\mathrm{GHz}$ range. The heavy damping plus the

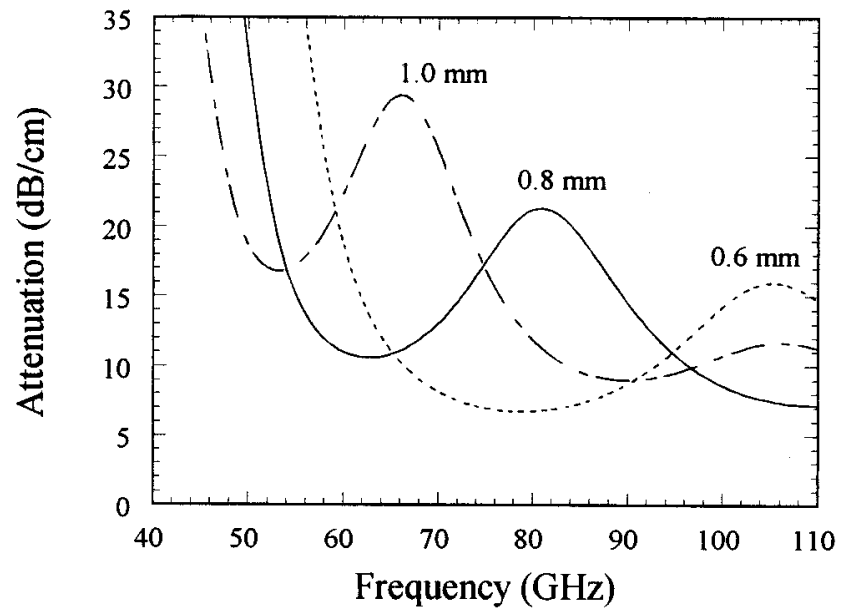

Fig. 6. Drift tube attenuation per unit length as a function of frequency for the $\mathrm{HE}_{12}$ mode, for three different values of radial dielectric thickness.

absence of field energy in the vacuum region completely eliminates any chance of oscillation. The third backward-wave and the forward-wave intersections lie on the $\mathrm{HE}_{12}$-mode, which is related to the dielectric-free $\mathrm{TE}_{12}$-mode. This hybrid mode has a modest portion of its field energy inside the dielectric, which leads to loading, and the remaining field structure in the vacuum region remains nearly identical to that of the dielectric-free $\mathrm{TE}_{11}$-mode. The similarity of this particular field structure to a vacuum solution in an $r=a$ cylindrical waveguide allows the effect of lossy dielectric to be approximately modeled as a simple resistive wall loss, greatly simplifying the computation of the loaded start-oscillation conditions by test particle or Vlasov methods.

The results of calculations of attenuation rate versus frequency in the vicinity of the $\mathrm{HE}_{12}$ backward-wave intersection point are shown in Fig. 6, for three different values of radial dielectric thickness. A radial thickness of $0.8 \mathrm{~mm}$ creates a peak attenuation of $20 \mathrm{~dB} / \mathrm{cm}$ that is well positioned to load the 76-GHz backward-wave oscillation. A similar computation of the drift tube loading near the $119-\mathrm{GHz}$ forward-wave intersection, performed for the $0.8-\mathrm{mm}$ thick case, indicated that the loaded quality factor remains below 30 at frequencies up to $140 \mathrm{GHz}$. Because this value is well below the starting $Q$ of 200, stability to a cavity-like oscillation is easily ensured. As a result of these computations, a dielectric thickness of $0.8 \mathrm{~mm}$ was adopted for the experiments.

During this extensive design procedure for the gun, circuit, collector, and window, detailed thermal and mechanical stress analysis was also carried out. At the completion of the final electrical and mechanical design of the device reported on herein, the amplifier had been thoroughly analyzed from the physics, electrical, and mechanical engineering points of view.

\section{EXPERIMENTAL TEST RESUlTS}

Device fabrication was carried out during mid-1997 to mid1998. The resulting gyroklystron is shown in Fig. 7, prior to initial testing. A liquid-helium-cooled NbTi superconducting magnet was employed for all of the testing described in the 


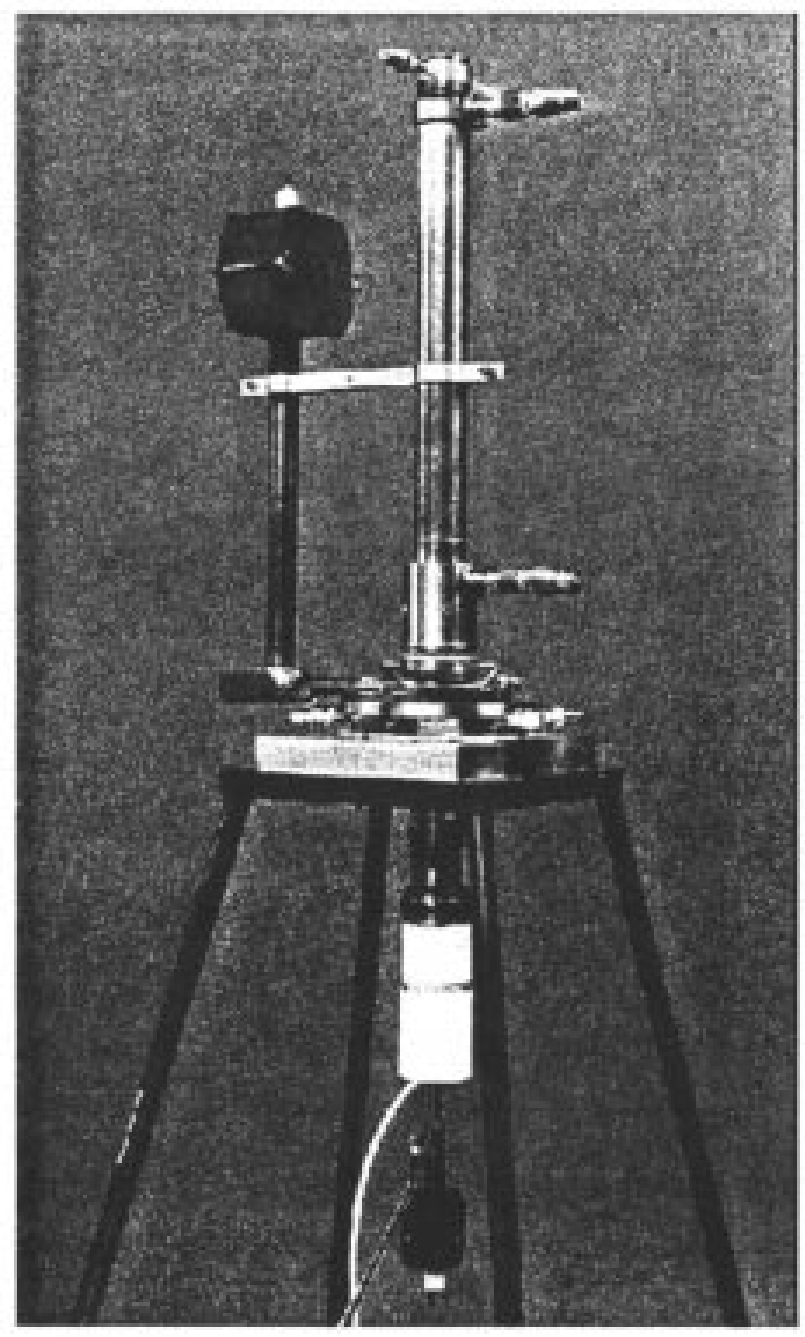

Fig. 7. Photograph of $94 \mathrm{GHz}$ gyroklystron

subsequent sections. Eventual system application of this gyroklystron will use closed-cycle-cooled superconducting magnets of either NbTi or high-temperature superconductor (HTS) [38] construction, but these magnets were not completed in time for the testing reported in this paper.

Experimental testing of this device was carried out from August 1998 through March 1999. The testing was divided into two parts, a low-duty-factor testing period (August 1998-October 1998) and a high-duty-factor testing period (October 1998-March 1999). Extensive measurements of the RF performance were made initially as part of the low-duty-factor testing period to characterize the RF peak-power performance of the amplifier.

Two different drivers were used in the experimental demonstration. For low-duty-factor testing $(<0.2 \% \mathrm{RF}$ duty factor), the drive power was supplied by an extended interaction oscillator (EIO), which is mechanically tunable from approximately 92.5 $\mathrm{GHz}$ to $95.5 \mathrm{GHz}$. The EIO produces up to $1.6-\mathrm{kW}$ peak output power at pulse lengths up to $2 \mu \mathrm{s}$. For high-duty-factor testing, a coupled-cavity TWT (CPI VTW-6495) amplifier (TWTA) was used, together with a frequency synthesized solid-state source. This TWTA produces up to $80-\mathrm{W}$ peak output power over the 93-GHz to $95-\mathrm{GHz}$ frequency range at duty factors up to $100 \%$

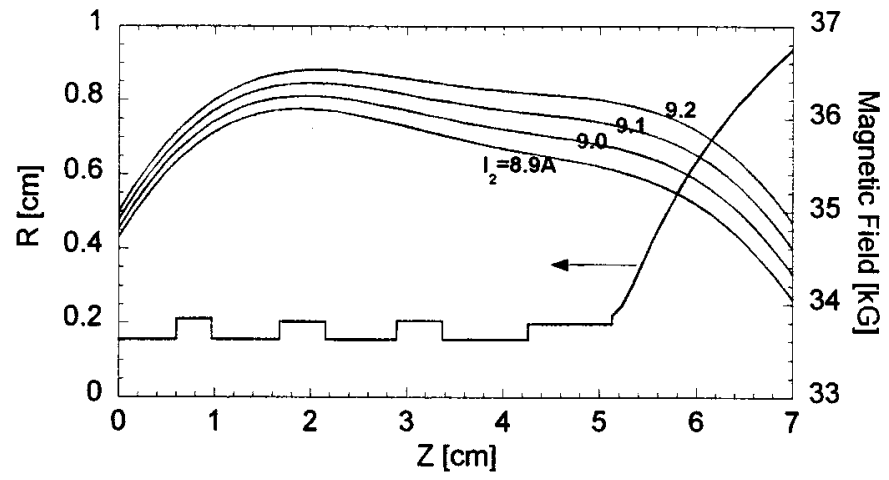

Fig. 8. Calculated field profile and field location with respect to circuit for constant $I_{1}=9.65$ A and varying $I_{2}$ currents used in experimental study.

$(\mathrm{CW})$. The drive power is measured with a calibrated directional coupler at the gyroklystron input flange, and the frequency of the input and output RF signals were measured with a spectrum analyzer. Losses in the drive line between the source and gyrotron input flange were found to be approximately $3 \mathrm{~dB}$. A water load was positioned on the atmospheric side of the output vacuum window, and the temperature rise of the water for a given volumetric flow rate was used to measure the average RF power. In the experimental testing, the mod-anode voltage was provided by a compensated resistive divider network connected between the cathode and ground.

During the low-duty-factor testing, parametric studies of circuit operation with beam current and magnetic field variations were made at low RF and beam duty-factor to determine the best operating point for subsequent high-duty-factor operation. The solenoid consisted of a pair of main coils over the circuit, with each coil excited by a separate current, denoted $I_{1}$ and $I_{2}$. Generally, the current in the coil closest to the electron gun was fixed at $I_{1}=9.65 \mathrm{~A}$, and the second coil (current $I_{2}$ ) was used to vary the magnetic field over the circuit. $I_{2}$ was typically varied in the range of $I_{2}=8.9$ A to $I_{2}=9.2 \mathrm{~A}$, corresponding to a variation of between $400-800 \mathrm{G}$ over the circuit. The field profiles obtained with these settings and the relative placement to the circuit is shown in Fig. 8. As shown in Fig. 9, the gyroklystron produced up to $118-\mathrm{kW}$ peak output power and $29.5 \%$ efficiency in the $\mathrm{TE}_{011}$-mode using a $66.7-\mathrm{kV}, 6-\mathrm{A}$ electron beam at $0.2 \%$ RF duty factor. At this operating point, the instantaneous full-width half-maximum (FWHM) bandwidth was $600 \mathrm{MHz}$ and the gain was $24.7 \mathrm{~dB}$. At higher magnetic fields, the bandwidth increases and the peak output power and gain decrease. This trend is predicted by the theoretical model, which shows that at lower fields, the input cavity operates in the negative beam-loading regime, which increases the $Q$ of this cavity and leads to lower bandwidth and higher gain and output power. As the magnetic field is increased, the cavity moves into the positive beam-loading regime, where the positive beam $Q$ decreases the overall $Q$ of the cavity, resulting in wider bandwidth and lower gain and output power. This behavior has also been documented in other detailed studies of bandwidth in gyroklystrons [39].

Also evident in Fig. 9 is the ripple in the peak output power across the frequency band. This effect has been determined to be caused by small reflections from the CVD diamond window. 


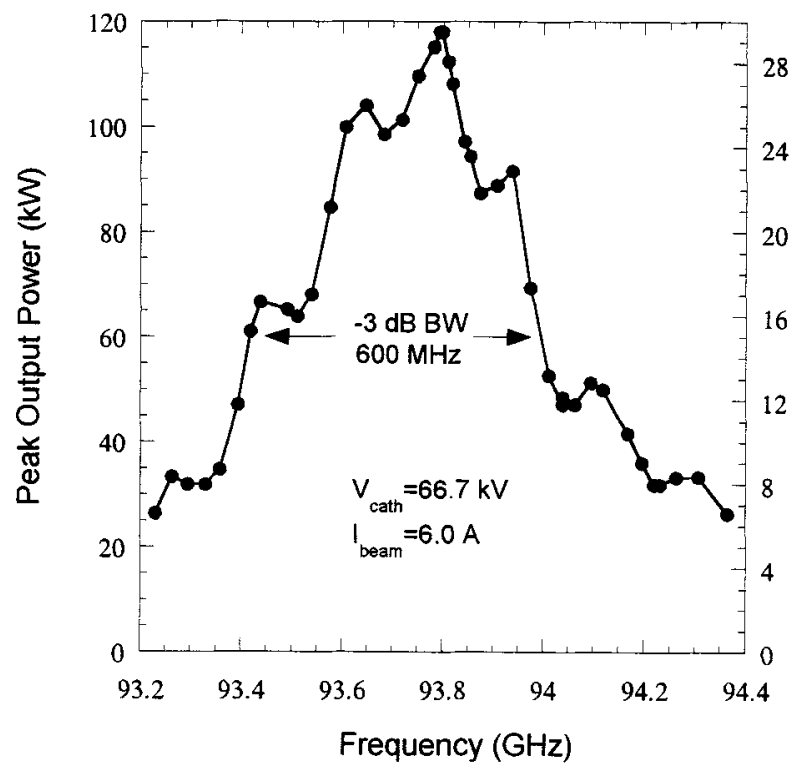

Fig. 9. Measured peak output power and efficiency versus frequency a 66.7 $\mathrm{kV}, 6$ A electron beam.

The reflected wave, depending on the round-trip phase shift between the output cavity and window, can add either in phase or out of phase with the cavity fields. Because this phase shift is frequency dependent, the window reflection results in the modulation of the output power across the frequency band as a function of drive frequency. This effect was modeled with the MAGY code. The code showed that the spacing and amplitude of the output power across the band is consistent with reflections from the output window (see next section). The code also showed that the amplitude of the ripple is reduced at higher magnetic fields, as was observed experimentally. More detailed theoretical analyzes of the measured data will be presented in a companion paper [40].

Upon completion of the low-duty-factor demonstrations, the EIO was replaced with the 100-W coupled cavity TWTA driver for high-duty-factor tests. Because of input power limitations, a high-gain operating point was chosen for the high-duty-factor tests. During initial operation at high-duty-factor, $1.5-\mathrm{kW}$ average power operation was achieved, and then upon increasing the duty factor to $2-\mathrm{kW}$ average power, the output window developed a slow air-to- vacuum leak. The leak was patched, and subsequent testing of the window found anomalously high RF absorption in the diamond window. In addition, detailed simulations of the beam trajectories in the collector, including the trajectories of multiply scattered primary electrons, predicted that a small current could reach the output window. A minor flaw in the diamond window, if present, could also have contributed to the leak. Although all three factors (high RF absorption, possibility of flaw, and stray reflected primary electrons) could have contributed to the window failure, it was not determined conclusively which of the possibilities was the cause for failure. The remedy applied in the rebuilt tube was a new, lower loss diamond window, and an additional transverse beam-dump magnet near the output window. The dielectric loss tangent for the new window was measured, and the window was determined to have approximately $10 \mathrm{~dB}$ lower losses than does the first window.

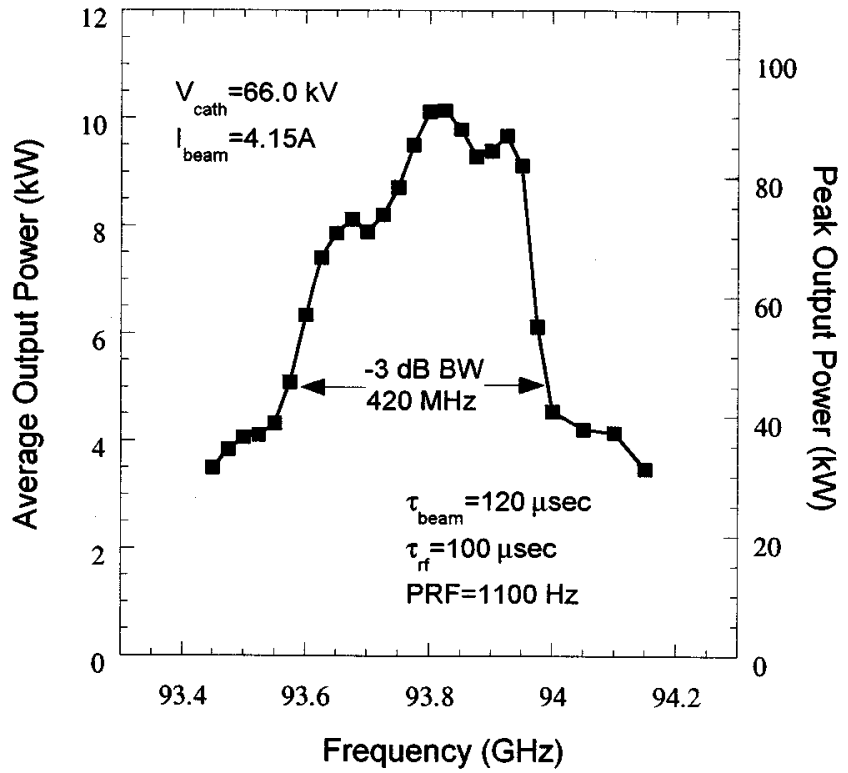

Fig. 10. Measured average and peak output power for a $66 \mathrm{kV}, 4.15$ A electron beam and $11 \%$ duty factor.

The new window was installed, the gyroklystron reprocessed, and testing resumed.

Following a check that confirmed the same low-duty-factor operation with the reprocessed tube, the high-duty-factor testing was resumed. High average power operation was achieved in short order. Fig. 10 shows the measured peak and average output power versus drive frequency for a $66-\mathrm{kV}$, 4.15-A electron beam. The RF pulsewidth was $100 \mu \mathrm{s}$, and the pulse repetition frequency was $1.1 \mathrm{kHz}$, corresponding to $11 \% \mathrm{RF}$ duty factor. The gyroklystron produced $10.1-\mathrm{kW}$ average output power, corresponding to $92-\mathrm{kW}$ peak output power and $33.5 \%$ efficiency. The measured FWHM bandwidth was $420 \mathrm{MHz}$. Fig. 11 shows the average output power and gain versus drive power. As shown in the figure, the maximum average output power of $10.1 \mathrm{~kW}$ and peak power of $92 \mathrm{~kW}$ is achieved for $53-\mathrm{W}$ peak driver power, corresponding to $32-\mathrm{dB}$ gain. High average power testing was halted at $11 \%$ duty factor rather than the designed $12.5 \%$ because of modulator limitations.

During high-duty-factor testing, the bandwidth of $420 \mathrm{MHz}$ was obtained, compared with the 600-MHz bandwidth obtained in low-duty-factor testing. This inability to reach $600 \mathrm{MHz}$ in high-duty-factor testing resulted from the limitations of the test set and the TWTA driver. In order to achieve the $10-\mathrm{kW}$ average power with the limited power available from the TWTA driver, it was necessary to operate the gyroklystron at the lower magnetic field parameters that gave narrower bandwidth and higher gain. It is believed that with a higher power driver, or with a few decibels additional gain, the $600-\mathrm{MHz}$ bandwidth achieved in low-duty-factor testing would be achieved at high duty factor. A second gyroklystron presently under development is expected to remedy this situation.

Fig. 12 shows the peak output power versus drive frequency for RF pulsewidths of $10 \mu \mathrm{s}, 40 \mu \mathrm{s}$, and $70 \mu \mathrm{s}$. For each curve, the beam current and beam voltage pulsewidths were held fixed at $90 \mu \mathrm{s}$, and the pulse repetition frequency was $1 \mathrm{kHz}$. As 


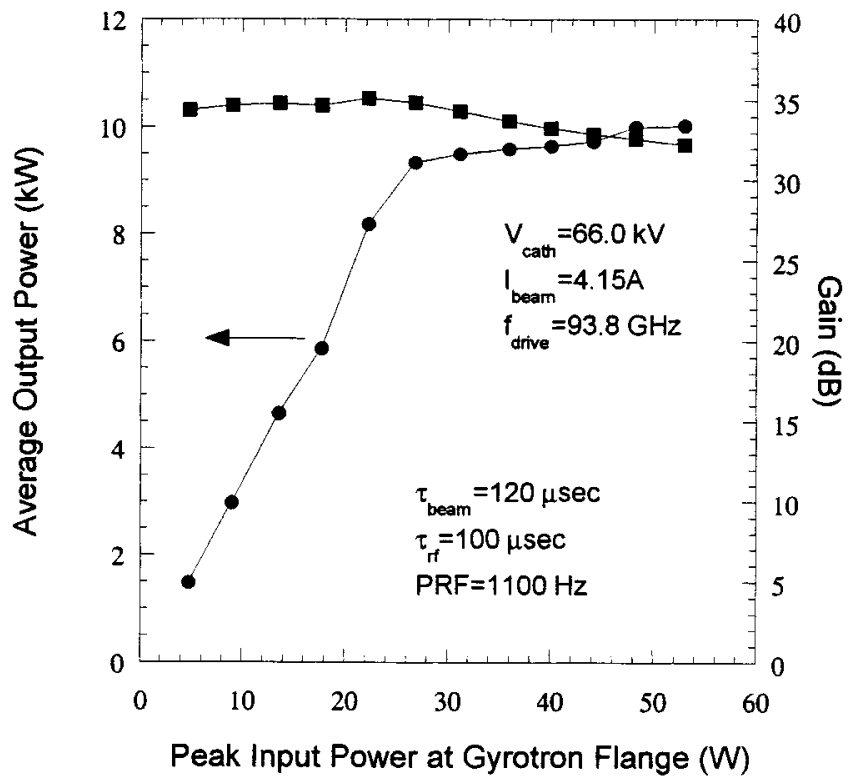

Fig. 11. Measured average output power and gain for a $66 \mathrm{kV}, 4.15 \mathrm{~A}$ electron beam and $11 \%$ rf duty factor. The drive frequency was held fixed at $93.8 \mathrm{GHz}$.

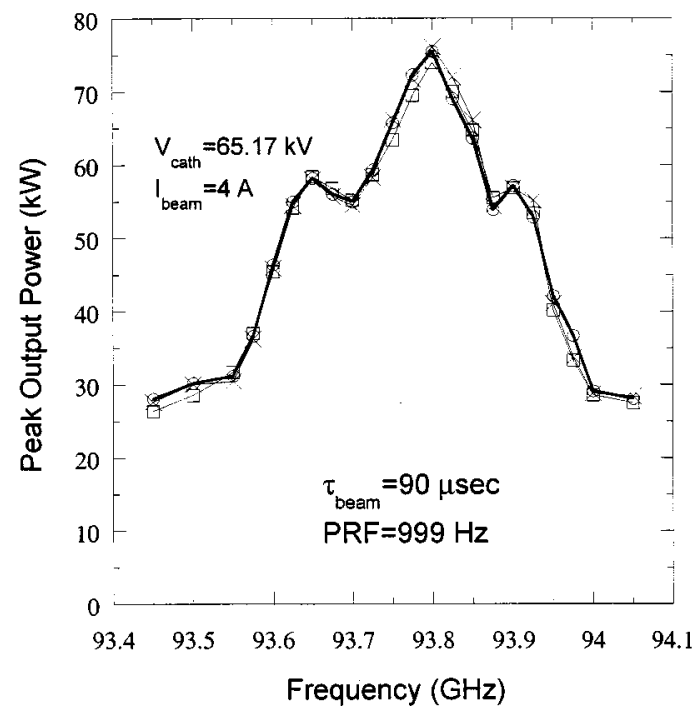

Fig. 12. Peak output power for RF beam pulse widths of $10 \mu$ s (open circle), $40 \mu \mathrm{s}$ (open square), and $70 \mu \mathrm{s}$ (x). For each curve, the beam pulse width, pulse repetition frequency, beam current, beam voltage, and all other parameters were held fixed.

seen in the figure, for RF duty factors ranging from $1 \%(10-\mu \mathrm{s}$ pulsewidth) to $7 \%$ (70- $\mu$ s pulsewidth), the differences in peak output power over the operating bandwidth were negligible. The measured results show that for duty factors in this range (1-7\%), there were no significant changes in the circuit or circuit performance resulting from thermal effects. In addition, circuit heating from RF losses, as measured by independent cooling loops, was at the nominal (calculated) values up to the full duty factor tested $(11 \%)$.

Parametric studies were also performed at high duty factor. By increasing the magnetic field, bandwidths up to $600 \mathrm{MHz}$ could be obtained with reduced peak and average output powers, typically, near $50 \mathrm{~kW}$ and $5 \mathrm{~kW}$, respectively. The theoretically predicted trend of a reduction in the ripple on the gain frequency response at the higher magnetic fields was also observed at high duty factor. In addition, calorimetric measurements were made for the window, the interaction circuit, and other cooled components of the device and were found to be close to the theoretically predicted values of losses.

In early April 1999, testing was completed and the gyroklystron was removed from the test stand at Communications and Power Industries (CPI). The gyroklystron has subsequently been shipped to NRL for delivery to the NRL Radar Division.

\section{ANALYSIS AND DisCUSSION}

In order to gain insights into the performance of the gyroklystron, a series of simulations with the time-dependent, self-consistent code MAGY [22] have been performed. In contrast to the model used in MAGYKL [20], MAGY does not assume $a$ priori the axial RF field profiles; rather, the field profiles are allowed to evolve self-consistently in response to beam-wave interactions. This capability is crucial for accurately predicting some phenomena in gyroklystrons. More detailed discussion on self-consistent effects in gyroklystrons is presented in a separate paper in this issue [40]. In addition, a model for window reflections is incorporated into MAGY, thus permitting evaluation of the experimentally observed ripples in frequency response.

A detailed comparison of experimental data and numerical simulations has been carried out for two operating beam currents, $4 \mathrm{~A}$ and $6 \mathrm{~A}$, and for a range of magnetic field values. Both frequency response curves (output power versus drive frequency) and drive curves (output power versus input power) have been compared. A representative sample of these numerous comparisons is presented here.

Shown in Fig. 13 are the comparison between experimental data and MAGY simulation of the frequency response (a) and drive curve (b) for a beam current of $4 \mathrm{~A}$, at given magnetic field values determined by superconducting solenoid currents $I_{1}=$ $9.65 \mathrm{~A}$ and $I_{2}=9.0 \mathrm{~A}$. The cold-cavity resonance frequencies and quality factors used in the simulations are as shown in Table II. These values agree with cold-test values within the experimental uncertainty of the cold-test measurement technique at the time the cold tests were performed [31]. The input powers shown were measured at the input flange and include the 3-dB known loss between this flange and the $\mathrm{TE}_{01}$ cavity.

Because the actual beam $\alpha$ was not measured directly, it was determined via a combination of the output cavity $\mathrm{TE}_{01}$ start-oscillation data and EGUN scaling of the magnetron injection gun design [25]. The methodology for determining the beam velocity ratio $\alpha$ is as follows. A series of MAGY simulations are first performed for a given beam current and magnetic field profile to determine the threshold $\alpha$ at which the output cavity begins to oscillate. Simulations with small variations below the start oscillation $\alpha$ are then performed to determine the beam $\alpha$ that best matches a set of experimental bandwidth and drive curves obtained just below the start-oscillation threshold. This provides us with the base $\alpha$ from which beam $\alpha$ for other sets of data can be determined, with EGUN scaling based on the relative change of the experimentally known gun voltages or magnetic field. In the EGUN scaling and in MAGY simulations, the 


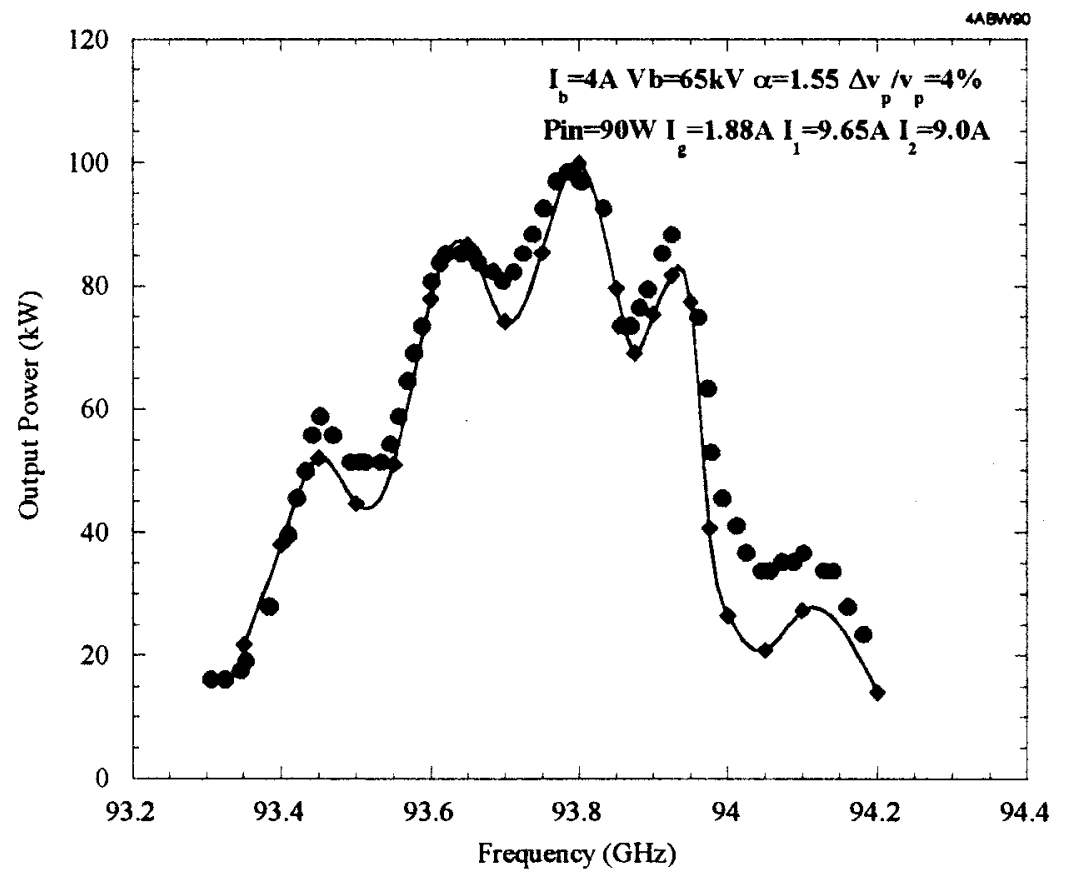

(a)

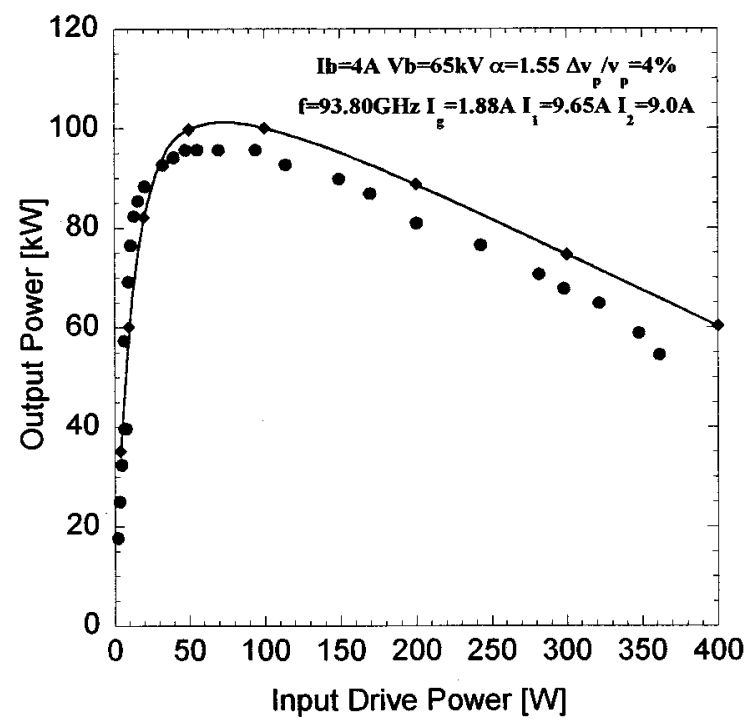

(b)

Fig. 13. Comparison of MAGY code and experimental data for $4 \mathrm{~A}$ beam current, and at magnetic field given by $I 2=9.0 \mathrm{~A}$ for both the frequency response (a) and the drive curve (b). Solid curves with diamond markers is code prediction; filled circles are experimentally measured data.

TABLE II

CAVITy Resonance FREQuenCy AND QUALITY FACTOR USED IN MAGY SIMULATIONS

\begin{tabular}{l|l|l}
\hline & $\begin{array}{l}\text { Resonance } \\
\text { Frequency } \\
(\mathrm{GHz})\end{array}$ & Quality Factor \\
\hline $\begin{array}{l}\text { Input Cavity } \\
\text { (Cavity 1) }\end{array}$ & 93.28 & $\begin{array}{l}\mathrm{Q}_{\mathrm{ext}}=155 \\
\mathrm{Q}_{\mathrm{Ohm}}=800\end{array}$ \\
\hline Cavity 2 & 94.24 & 150 \\
\hline Cavity 3 & 92.91 & 150 \\
\hline $\begin{array}{l}\text { Output Cavity } \\
\text { (Cavity 4) }\end{array}$ & 93.62 & 165 \\
\hline
\end{tabular}

magnetic field profiles used are obtained with the magnetic field code EFFI [41], using actual experimental settings of the superconducting coils. The EFFI calculated and measured axial magnetic field profiles have been compared and found to be in excellent agreement. In addition, a window reflection of $1 \%(-20-\mathrm{dB}$ return loss) from the CVD diamond window, based on cold-test measurements, has also been incorporated into the MAGY simulations shown in Fig. 13. Fig. 14 shows a similar comparison between experimental data and the MAGY code predictions for the case of a 6-A beam current. The excellent agreement between the experimental data and the simulations provides compelling evidence that the observed frequency response ripple can indeed be attributed to the small window reflection. In addition, 


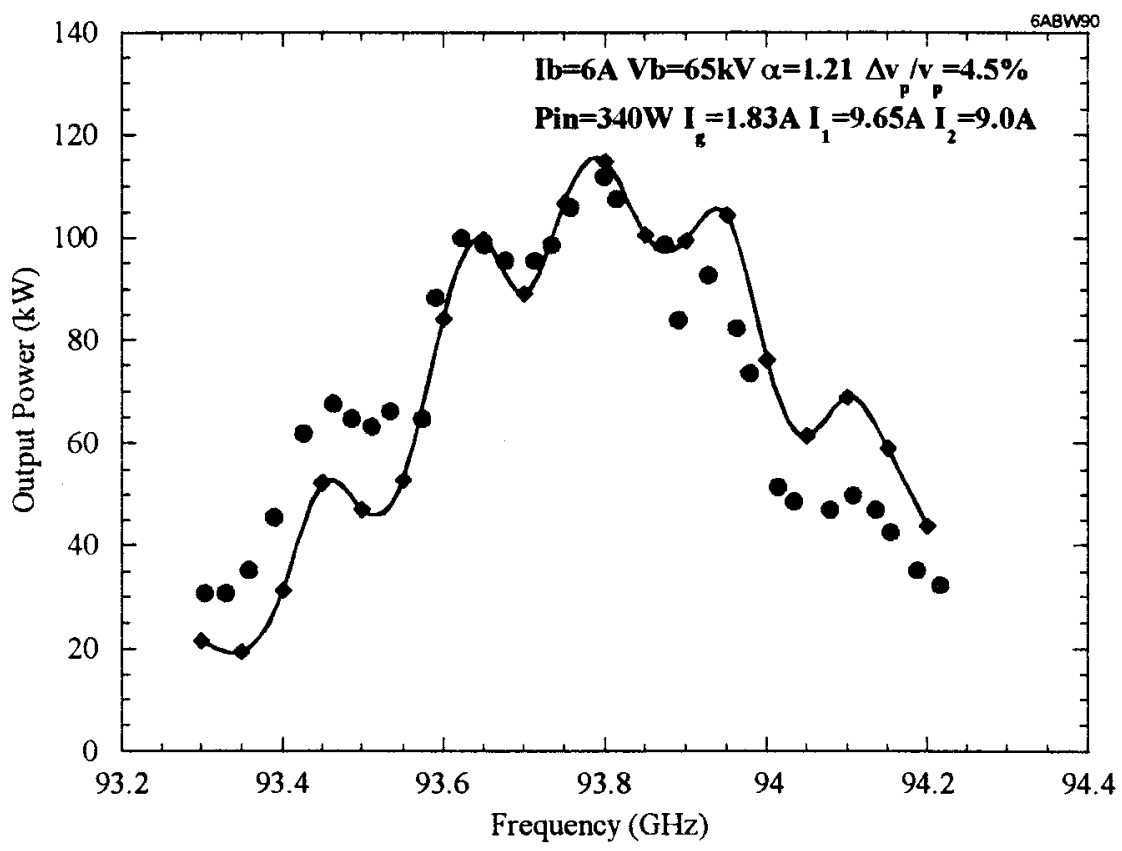

(a)

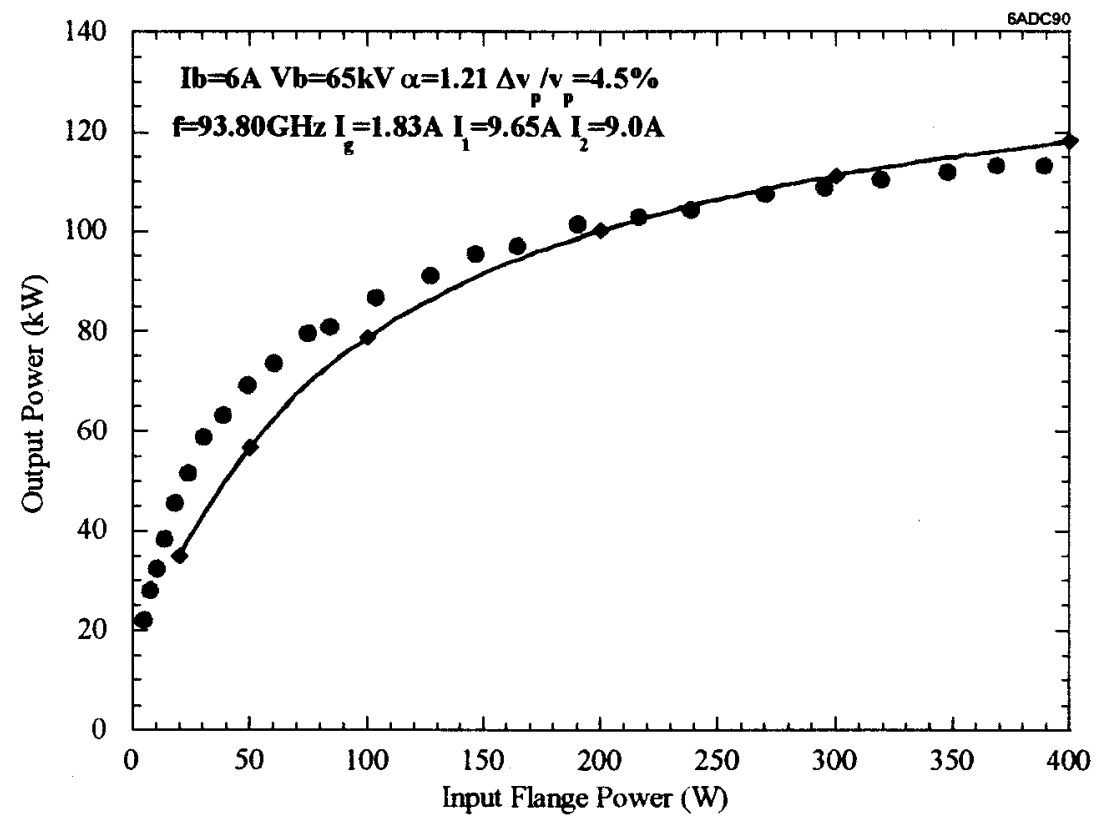

(b)

Fig. 14. Comparison of MAGY code and experimental data for $6 \mathrm{~A}$ beam current, and at magnetic field given by $I 2=9.0 \mathrm{~A}$ for both the frequency response (a) and the drive curve (b). Solid curves with diamond markers is code prediction; filled circles are experimentally measured data.

it is clear that the overall performance of the gyroklystron is well modeled by the MAGY code.

As a practical note, although this ripple in frequency response is nonideal, it is of relatively minor consequence in the radar application. Plotted on a logarithmic scale, it amounts to on the order of \pm 0.5 - $\mathrm{dB}$ variation from the no-reflection curves; this level of variation is straightforward to remove in the radar signal processing. Nevertheless, one of the goals for subsequent devices currently under development is a reduction of this frequency response ripple.

\section{CONCLUSION}

In summary, a four-cavity, $\mathrm{TE}_{011}$-mode, high-average-power gyroklystron amplifier was designed, built successfully, and tested. The successful development, in a single generation, of this high average power device is a testament to both the validity of the design procedure and the quality of the physical models and corresponding computer codes that were employed in this effort. At low duty factor, the amplifier produced up to $118-\mathrm{kW}$ peak output power at $600-\mathrm{MHz}$ bandwidth. At high duty factor, 
10.1-kW average output power and $420-\mathrm{MHz}$ bandwidth were achieved at $11 \%$ RF duty factor with an efficiency of $33.5 \%$. At different magnetic field settings, the device produced $600-\mathrm{MHz}$ instantaneous bandwidth with $5-\mathrm{kW}$ average power and 50-kW peak power. These results represent world-record-setting performance for an amplifier at this frequency.

Future work will be centered on improving certain aspects of the device performance. Because of the limited availability and high cost of high-duty-factor drivers with tens of watts of power at millimeter-wave frequencies, future work will be focused on improving device gain, in anticipation of being able to saturate with solid-state drivers in subsequent devices. A subsequent amplifier currently in construction will comprise five cavities to improve the gain of the device by more than $10 \mathrm{~dB}$. Future work will also consider bandwidth improvement by replacing the output cavity with a traveling-wave output section, a configuration commonly referred to as a gyrotwystron amplifier. A low-duty-factor prototype of a W-band gyrotwystron has demonstrated 50-kW peak output power and 925-MHz FWHM bandwidth, and calculations of projected performance with the present electron gun design are for $1.4-\mathrm{GHz}$ bandwidth at 80-kW peak power level [42]. For bandwidths greater than $2 \mathrm{GHz}$, gyro-TWT amplifiers are under investigation by a number of researchers [43]-[45], and there is ample reason to be optimistic about the future development of high average power versions of gyro-TWT's in the millimeter-wave band.

\section{ACKNOWLEDGMENT}

The encouragement and support of I. Mack and G. Borsuk is gratefully acknowledged. The authors would also like to thank V. Gregers-Hansen for his frequent technical feedback on the choice of RF design parameters during the initial stages of this effort. The authors would like to acknowledge the contributions of N. Dionne, for his help in the collector analysis, S. Cooke and J. Petillo for their analysis of the RF circuit, S. Caufman for help in early stages of design, and J. Feinstein for his always insightful comments. The important contributions of J. Hirshfield in many facets of this effort are also gratefully acknowledged. The authors also thank R. Heidinger, R. Spörl, and M. Thumm for window loss measurements.

\section{REFERENCES}

[1] V. A. Flyagin et al., "The gyrotron," IEEE Trans. Microw. Theory Tech., vol. MTT-25, pp. 514-521, 1977.

[2] K. L. Felch, B. G. Danly, H. R. Jory, K. E. Kreischer, W. G. Lawson, B. Levush, and R. J. Temkin, "Characteristics and applications of fast-wave gyrodevices," Proc. IEEE, vol. 87, pp. 752-781, May 1999.

[3] V. Erckmann, G. Dammertz, D. Dorst, L. Empacher, W. Förster, G. Gantenbein, T. Geist, W. Kasparek, H. P. Laqua, G. A. Müller, M. Thumm, $M$. Weissgerber, and H. Wobig, "ECRH and ECCD with high power gyrotrons at the stellarators W7-AS and W7-X," IEEE Trans. Plasma Sci., vol. 27, pp. 538-546, Feb. 1999.

[4] G. Link, L. Feher, M. Thumm, H. J. Ritzhaupt-Kleissl, R. Böhme, and A. Weisenburger, "Sintering of advanced ceramics using a 30-GHz, 10-kW, CW industrial gyrotron," IEEE Trans. Plasma Sci., vol. 27, pp. 547-554, Feb. 1999.

[5] L. R. Becerra, G. J. Gerfen, R. J. Temkin, D. J. Single, and R. G. Griffin, "Dynamic nuclear polarization with a cyclotron resonance maser at 5T," Phys. Rev. Lett., vol. 71, no. 3561, p. 3564, 1993.

[6] V. L. Granatstein and W. G. Lawson, "Gyro-amplifiers as candidate RF drivers for TeV linear colliders," IEEE Trans. Plasma Sci., vol. 24, no. 3, pp. 648-665, 1996.
[7] D. R. Lohrmann, "Millimeter wave radars tracking approaching sea skimming targets," in Proc. 22nd Int. Conf. Infrared Millimeter Waves, 1997, pp. 39-41.

[8] L. A. Hoffman, K. H. Hurlbut, D. E. Kind, and H. J. Wintroub, "A 94-GHz radar for space object identification," IEEE Trans. Microw. Theory Tech., vol. MTT-17, pp. 1145-1149, Dec. 1969.

[9] M. D. Abouzahra and R. K. Avent, "The $100 \mathrm{~kW}$ millimeter-wave radar at the Kwajalein atoll," IEEE Antennas Propagat. Mag., vol. 36, no. 2, pp. 7-19, 1994.

[10] W. M. Manheimer, G. Mesyats, and M. I. Petelin, "Applications of highpower microwave sources to enhanced radar systems," in Applications of High Power Microwaves, A. V. Gaponov-Grekhov and V. L. Granatstein, Eds. Boston: Artech House, 1994, pp. 169-207.

[11] A. A. Tolkachev, V. V. Denisenko, A. V. Shishlov, and A. G. Shubov, "High gain and high power antenna systems for advanced multifunction millimeter wave radars," in Proc. 1996 CIE Int. Conf. Radar, L. Nengjing, Z. Siyong, and L. Zhiwen, Eds., 1996, pp. 499-502.

[12] A. A. Tolkachev, V. Trushin, and V. Veitsel, "On the possibility of using powerful millimeter wave band radars for tracking objects in circumterrestrial space," in Proc. CIE Int. Conf. Radar, L. Nengjing, Z. Siyong, and L. Zhiwen, Eds., 1996, pp. 629-632.

[13] A. A. Tolkachev, "Gyroklystron-based $35 \mathrm{GHz}$ radar for observation of space objects," in Proc. 22nd Int. Conf. Infrared Millimeter Waves, H. P. Freund, Ed., 1997, pp. 37-38.

[14] I. I. Antakov, E. V. Zasypkin, and E. V. Sokolov, "Design and performance of $94 \mathrm{GHz}$ high power multicavity gyroklystron amplifier," in Proc. 18th Int. Conf. Infrared Millimeter Waves, 1993, pp. 466-467.

[15] I. I. Antakov, E. V. Sokolov, and E. V. Zasypkin, "Design and performance of $94 \mathrm{GHz}$ high power multicavity gyroklystron amplifier," in Proc. Int. Workshop Strong Microw. Plasma, A. G. Litvak, Ed., 1994, pp. $754-758$.

[16] M. Blank, B. G. Danly, B. Levush, J. P. Calame, K. T. Nguyen, D. E. Pershing, J. Petillo, T. A. Hargreaves, R. B. True, A. J. Theiss, G. R. Good, K. L. Felch, B. G. James, P. Borchard, P. Cahalan, T. S. Chu, H. R. Jory, W. G. Lawson, and T. M. Antonsen, Jr., "Demonstration of a 10 $\mathrm{kW}$ average power $94 \mathrm{GHz}$ gyroklystron amplifier," Phys. Plasmas, vol. 6, no. 12, pp. 4405-4409, 1999.

[17] M. Blank, B. G. Danly, B. Levush, and P. E. Latham, "Experimental demonstration of a W-band gyroklystron amplifier," Phys. Rev. Lett., vol. 79, pp. 4485-4488, 1997.

[18] M. Blank, B. G. Danly, B. Levush, and D. E. Pershing, "Experimental invesitgation of W-band $(93 \mathrm{GHz})$ gyroklystron amplifiers," IEEE Trans. Plasma Sci., vol. 26, pp. 409-415, June 1998.

[19] M. Blank, B. G. Danly, and B. Levush, "Experimental demonstration of W-band gyroklystron amplifier with improved gain and efficiency," IEEE Trans. Plasma Sci., vol. 28, pp. 706-712, June 2000.

[20] P. E. Latham, W. G. Lawson, and V. Irwin, "The design of a $100 \mathrm{MW}$ Ku band second harmonic gyroklystron experment," IEEE Trans. Plasma Sci., vol. 22, pp. 804-817, Oct. 1994.

[21] J. M. Neilson, P. E. Latham, M. Caplan, and W. G. Lawson, "Determination of the resonant frequencies in a complex cavity using the scattering matrix formalism," IEEE Trans. Microw. Theory Tech., vol. 37, pp. $1165-1170,1989$.

[22] M. Botton, T. M. Antonsen Jr, B. Levush, K. T. Nguyen, and A. N. Vlasov, "MAGY: A time dependent code for simulation of slow and fast microwave sources," IEEE Trans. Plasma Sci., vol. 26, pp. 882-892, June 1998.

[23] P. E. Latham, S. M. Miller, and S. G. Tantawi, "Use of lie transforms to generalize Madey's theorem for computing the gain in microwave devices," Phys. Rev. A, vol. 45, no. 2, pp. 1197-1205, 1992.

[24] B. Levush, M. Blank, J. P. Calame, B. G. Danly, K. T. Nguyen, D. E. Pershing, S. J. Cooke, P. E. Latham, J. Petillo, and T. M. Antonsen Jr, "Modeling and design of millimeter wave gyroklystrons," Phys. Plasmas, vol. 6, no. 5, pp. 2233-2240, 1999.

[25] K. T. Nguyen, B. G. Danly, B. Levush, M. Blank, R. B. True, G. R. Good, T. A. Hargreaves, K. Felch, and P. Borchard, "Electron gun and collector design for $94 \mathrm{GHz}$ gyro-amplifiers," IEEE Trans. Plasma Sci., vol. 26, pp. 799-813, June 1998.

[26] M. Blank, B. G. Danly, and B. Levush, "Circuit design of a wideband W-band gyroklystron amplifier for radar applications," IEEE Trans. Plasma Sci., vol. 26, pp. 426-432, June 1998.

[27] W. G. Lawson, "Theoretical evaluation of nonlinear tapers for a high-power gyrotron," IEEE Trans. Microw. Theory Tech., vol. 38, pp. 1617-1622, Nov. 1990.

[28] A. H. McCurdy and J. J. Choi, "Design and analysis of a coaxial coupler for a $35 \mathrm{GHz}$ gyroklystron amplifier," IEEE Trans. Microw. Theory Tech., vol. 47, pp. 164-175, Feb. 1999.

[29] Hewlett Packard Co., "High Frequency Structure Simulator (HFSS)," [4.01], 1997. 
[30] J. Petillo, A. Mankofsky, W. Krueger, C. Kostas, A. Mondelli, and A. Drobot, "Applications of the ARGUS code in accelerator physics," in Proc. Computat. Accelerator Phys. Conf., 1994, pp. 303-312.

[31] D. E. Pershing, A. H. McCurdy, B. G. Danly, J. M. Cameron, and M. Blank, "Dielectric probe development for W-band gyroklystron cavity testing," in Proc. 24th Int. Conf. Infrared Millimeter Waves, L. A. Lombardo, Ed., 1999, W-D3.

[32] HP., "Network analysis: Applying the HP8510 TRL calibration for noncoaxial measurements,", Hewlett Packard Product Note 8510-8A, 1999.

[33] — - "Millimeter wave measurements: Using the HP8510B network analyzer,", Hewlett Packard Product Note 8510-12, 1999.

[34] J. P. Calame and D. K. Abe, "Applications of advanced materials technologies to vacuum electronic devices," Proc. IEEE, vol. 87, pp. 840-864, May 1999.

[35] S. G. Tantawi, W. T. Main, P. E. Latham, G. S. Nusinovich, W. G. Lawson, C. D. Striffer, and V. L. Granatstein, "High-power X-band amplification from an overmoded three-cavity gyroklystron with a tunable penultimate cavity," IEEE Trans. Plasma Sci., vol. 20, pp. $205-215,1992$

[36] K. R. Chu and A. T. Lin, "Gain and bandwidth of the gyro-TWT and CARM amplifiers," IEEE Trans. Plasma Sci., vol. PS-16, pp. 90-103, Feb. 1988.

[37] R. F. Harrington, Time Harmonic Electromagnetic Fields. New York, NY: McGraw-Hill, 1961, pp. 219-223.

[38] D. Hazelton, B. G. Danly, and D. U. Gubser, "Cryogen-free high temperature superconducting magnet for $94 \mathrm{GHz}$ gyroklystron powered radar applications," Naval Engineers J., vol. 110, no. 1, pp. 117-121, 1998.

[39] J. P. Calame, M. Garven, J. J. Choi, K. T. Nguyen, F. Wood, M. Blank, B. G. Danly, and B. Levush, "Experimental studies of bandwidth and power production in a three-cavity $35 \mathrm{GHz}$ gyroklystron amplifier," Phys. Plasmas, vol. 6, no. 1, pp. 285-297, 1999.

[40] K. T. Nguyen, B. Levush, T. M. Antonsen Jr, M. Botton, M. Blank, and J. P. Calame, "Modeling of gyroklystrons with MAGY," IEEE Trans. Plasma Sci., vol. 28, pp. 867-886, June 2000.

[41] S. J. Sackett, Users Manual for EFFI. UCID-17621. Livermore, CA: Lawrence Livermore National Laboratory, 1981.

[42] M. Blank, B. G. Danly, and B. Levush, "Experimental demonstration of a W-band (94 GHz) gyrotwystron amplifier," IEEE Trans. Plasma Sci., vol. 27, pp. 405-411, Apr. 1999.

[43] K. R. Chu, H. Y. Chen, C. L. Hung, T. H. Chang, L. R. Barnett, S. H. Chen, and T. T. Yang, "Ultra-high gain gyrotron traveling wave amplifier," Phy. Rev. Lett., vol. 81, no. 4760, p. 4763, 1998.

[44] G. G. Denisov, V. L. Bratman, A. D. R. Phelps, and S. V. Samsonov, "Gyro-TWT with a helical operating waveguide: New possibilities to enhance efficiency and frequency bandwidth," IEEE Trans. Plasma Sci., vol. 26, pp. 508-518, June 1998.

[45] D. B. McDermott, B. H. Deng, K. X. Liu, J. Van Meter, Q. S. Wang, and N. C. Luhmann Jr, "Stable 2-MW, 35-GHz, third-harmonic $\mathrm{TE}_{41}$ Gyro-TWT amplifier," IEEE Trans. Plasma Sci., vol. 26, pp. 482-487, June 1998.

Bruce G. Danly (M'87) received the B.A. degree in physics from Haverford College, and the Ph.D. degree in physics from the Massachusetts Institute of Technology, in 1978 and 1983, respectively. His doctoral dissertation in the area of quantum electronics was on high power infrared Raman lasers. From 1983 to 1995.

He was on the research staff at the MIT Plasma Fusion Center, first as Research Scientist from 1983-1992, and then as Principal Scientist from 1992-1995. While at MIT, he participated in research on gyrotrons, free-electron lasers, relativistic klystrons, and other high power RF source technologies for use in plasma heating and high-gradient RF linear accelerators. In 1995, he joined the Naval Research Laboratory as Head of the High Power Devices Section, Vacuum Electronics Branch. The high power devices section carries out experimental research and development on new concepts for high power microwave, millimeter wave, and infrared sources based on both slowwave and fastwave interaction mechanisms. Technologies under investigation include the class of gyrotron amplifiers (gyroklystrons, gyrotwystrons, gyro-TWT's), free-electron lasers, TWT's, and klystrons. In addition to his duties as head of the High Power Devices Section, he is also the Program Point of Contact for the High Performance Millimeter Wave Devices Program, administered by the NRL Vacuum Electronics Branch for the Office of Naval Research. This program carries out exploratory development of new high power amplifiers in the millimeter wave bands, in particular the Ka- and W-Bands.

Dr. Danly is a member of the APS and Divisions of Physics of Beams and Plasma Physics.
Monica Blank received the B.S. degree (electrical engineering) from the Catholic University of America, Washington, DC, in 1988, and the M.S. and $\mathrm{Ph} . \mathrm{D}$. degrees (electrical engineering) in 1991 and 1994, respectively, from the Massachusetts Institute of Technology, Cambridge, where her dissertation work involved theoretical and experimental studies of quasi-optical mode converters for high power gyrotron oscillators.

In 1994 she joined the Vacuum Electronics Branch of the Naval Research Laboratory, where she was responsible for the design and demonstration of high-power millimeter wave vacuum electronic devices for radar applications. In 1999 she joined the gyrotron team at Communications and Power Industries (formerly Varian) where she continues her work on high-power millimeter wave gyrotron amplifiers.

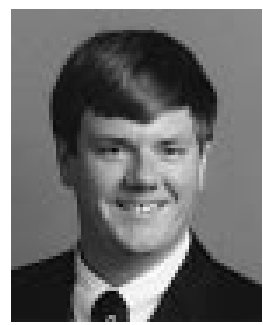

J. P. Calame (M'96) received the B.S. degree in 1985, the M.S. degree in 1986, and the Ph.D. degree in 1991, all in electrical engineering, from the University of Maryland, College Park.

He performed part-time research on the electrical behavior of ionic crystals and ion-conducting polymers at the U.S. Naval Academy Physics Department, Annapolis, MD, from 1980 to 1985. His graduate research from 1985 to 1991 involved the development of high peak power gyroklystrons. From 1991 to 1992, he worked with microfabricated field emission electron sources and devices at the Naval Research Laboratory, Washington, DC. From 1992 to 1997, he studied high-power microwave amplifiers, the microwave processing of materials, and the dielectric properties of ceramics at the Institute for Plasma Research, University of Maryland. Presently, he is with at the Naval Research Laboratory, where he is developing high average power, wideband millimeter-wave amplifiers for radar applications. He is also studying the dielectric and thermal properties of composite ceramic materials, and he is investigating intrinsic electronic noise in millimeter-wave systems.

Dr. Calame received the 1991 APS award for Outstanding Doctoral Thesis Research in Beam Physics.

Baruch Levush (M'88-SM'90) received the M.Sc. degree in physics from Latvian University, Riga, Latvia, in 1972 and the Ph.D. degree in physics from Tel-Aviv University, Tel-Aviv, Israel, in 1981

He received the Dr. Ch. Weizman Postdoctoral Fellowship and stayed for two years at the University of Maryland, College Park. From 1984 to 1985, he was a Research Scientist with Rafael Research Laboratory, Israel. In 1985, he joined the University of Maryland, where his research was focused on the physics of coherent radiation sources and the design of high-power microwave sources, such as gyrotrons, TWT's, BWO's, and free electron lasers. In 1993, he became a Senior Research Scientist at the Institute for Plasma Physics, University of Maryland. In 1995, he joined the Naval Research Laboratory, Washington, DC, as the Head of the Theory and Design Section of the Vacuum Electronics Branch. He is actively involved in developing theoretical models and computational tools for analyzing the operation of existing microwave vacuum devices and in inventing new concepts for high-power, high-frequency coherent radiation sources. He is the author and coauthor of more than 100 journal articles.

Dr. Levush is a Member of the American Physical Society.

Khanh T. Nguyen received the B.S. degree in physics and mathematics in 1978, the M.S. degree in mathematics in 1979, and the M.S. and the Ph.D degrees in nuclear science in 1980 and 1983, respectively, all from the University of Michigan, Ann Arbor. His Ph.D research topic was a stability study of the ELMO Bumpy Torus Fusion Device.

He then joined the Department of Research and Technology, Naval Surface Warfare Center, White Oak, where he was the Lead Theorist for the charged particle beam propagation experimental program. In 1989, he joined the Washington Office of Mission Research Corporation as a Senior Scientist, and later became the leader of the Electromagnetic Application Group. At MRC, his research efforts were in the areas of charged particle beam propagation, vacuum electronics, compact accelerator development, $\mathrm{x}$-ray and g-ray simulators, and high-power microwave sources development. Since 1994, when he initiated KN Research, he has been an on-site contractor with the Vacuum Electronics Branch, Naval Research Laboratory. His current research emphasis is on the design and modeling of vacuum electronic devices. 
Dean E. Pershing received the B.S. and the Ph.D. degrees in physics from North Carolina State University in 1971 and 1980, respectively.

In 1980, he continued research on the generation and propagation of intense electron and ion beams as a NRC/NRL Post-doctoral Research Associate while participating in the Naval Research Laboratory Ion Ring Program. From 1981-1983, he participated in the design of the Modified Betatron Accelerator at NRL, while a staff member of JAYCOR. Since joining Mission Research Corporation in 1983, his research has concentrated on the design and testing of high-power microwave amplifiers, including ubitron/FEL's and, most recently, gyroklystrons.

R. K. Parker, photograph and biography not available at the time of publication.

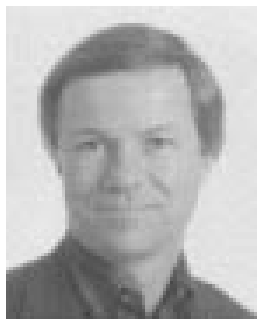

Kevin L. Felch (M'84) was born in Denver, CO, on December 7, 1952. He received the A.B. degree in physics from Colorado College, Colorado Springs, in 1975, and the Ph.D. degree in physics from Dartmouth College, Hanover, NH, in 1980. His graduate work involved the design and construction of a 400-kV 30-A electron-beam system and the use of dielectric-loaded waveguides in combination with the electron beam for the generation of millimeter-wave Cherenkov radiation.

During 1980, he held a postdoctoral position at the Ecole Polytechnique in Palaiseau, France. His work there involved the design, construction, and operation of a free-electron laser experiment. He joined Varian Associates, Inc., in 1981 as a member of the Gyrotron Engineering Department His work at Varian (now Communications and Power Industries) has involved the development of high-power gyrotron oscillators and amplifiers. He is currently the Team Leader for gyrotron activities at Communications and Power Industries.

Dr. Felch is a member of the Plasma Physics Division of the American Physical Society and the Plasma Science Society of the Institute of Electrical and Electronics Engineers. In 1985, he served as Guest Editor for a special topics issue of IEEE TRANSACTIONS ON PLASMA SCIENCE.

B. G. James, photograph and biography not available at the time of publication.

P. Borchard, photograph and biography not available at the time of publication.

P. Cahalan, photograph and biography not available at the time of publication.

T. S. Chu, photograph and biography not available at the time of publication.

Howard R. Jory (S'54-M'60-SM'90-F'94-LF'95) received the B.S. degree in electrical engineering from the University of California in 1954, the M.S. degree in 1955, and the Ph.D. degree in 1960.

From 1960 to 1962, he served as a First Lieutenant in the U.S. Army. He was assigned to the U.S. Army Signal Research and Development Laboratories at Fort Monmouth, NJ, as a Project Officer for microwave tube research and development. In 1962 he joined Varian Associates as an Engineer in the Research Department of the Tube Division where he worked on several projects involving high-power microwaves. From 1965 to 1968, he was a member of the Varian Central Research Laboratories. There he was a Research Group Manager and Project Engineer for several projects involving high-voltage electron beams and optical resonators for millimeter waves. From 1968 to 1972, he was a member of the Varian Radiation Division working with the design of accelerator systems, acoustic imaging devices and microwave heating systems. Since 1972, he has been in the Palo Alto Microwave Tube Division, working initially as a Project Engineer for coupled-cavity, traveling-wave tubes. In 1976, he started development work at Varian (now Communications and Power Industries) for gyrotrons to supply high-power millimeter waves for magnetic fusion research. This work has resulted in the development of numerous gyrotrons with frequencies ranging from 8 to $140 \mathrm{GHz}$ and power levels from $200 \mathrm{~kW}$ to $1 \mathrm{MW}$. During this time, he has served as Gyrotron Department Manager.
Thomas A. Hargreaves received the B.S. in mathematics (1976), M.S. in engineering-applied science (1978) and the Ph.D. in plasma physics (1982) from the University of California, Davis.

In 1991, he joined Litton Electron Devices as a Senior Scientist. In his 9 year tenure at Litton, he has been responsible for the design and development of fundamental and harmonic millimeter-wave devices, and high power klystrons. Prior to starting with Litton, Dr. Hargreaves worked for 8 years at the Naval Research Laboratory (NRL), Mission Research Corporation and JAYCOR where he worked on various gyro devices, magnetrons and electromagnetic pulse sources. Dr. Hargreaves is a Member of the American Physical Society and the IEEE, and is currently a Member of the IEEE Plasma Science and Applications Executive Committee.

Richard B. True (S'70-M'79-SM'83-F'93) received an Sc.B. in electrical engineering from Brown University in 1966, an M.S. in microwave engineering, and a Ph.D. in electrophysics from the University of Connecticut in 1968 and 1972 respectively. He worked as an Electrical Engineer for Raytheon Company in Portsmouth, RI, and for Microwave Associates in Burlington, MA, before joining Litton Systems, Inc., Electron Devices Division, in San Carlos, CA. Dr. True has been Chief Scientist at Litton EDD since 1991.

While at Litton, he has been engaged in various research and development programs (many involving his own inventions). He has extensive experience in the theory, design, and test of microwave tubes, and, over the years, has designed the gun, focussing system, multistage depressed collector, plus other key elements in most of the helix and coupled cavity travelling wave tubes in major production at Litton EDD, using theories and software that he originated. These tubes are used in advanced microwave and millimeter wave radars, communication, ECM, and missile systems. Further, he has experience in microwave systems, microwave power modules, and exotic microwave measurements. He also has analyzed and designed thermionic sources for high power klystrons, free electron lasers, linear accelerators, switch tubes, x-ray tubes, image intensifiers, cathode ray tubes, flood beam devices for toxic waste remediation, magnicons, gyroklystrons, and flat panel displays.

Dick also has served on the IEEE EDS AdCom, has been Associate Editor of the IEEE TRANSACTIONS ON ELECTRON DEVICES, and served on the Board of Directors of the AFTER Program at Stanford and the University of Utah. He has authored or co-authored 132 published papers (27 invited) and final reports, and he holds thirteen issued patents. His 1987 paper in the IEEE TRANSACTIONS ON ELECTRON DEVICES earned him the Paul Rappaport Award for the best paper of the year in an IEEE EDS publication, and in 1992 he won a Litton Industries Corporate Advanced Technology Award for his electron beam dynamics software. In 1997 he received a Litton Corporate Advanced Product Development Award for major redesign of a very difficult Dual-Mode TWT, and in 1999, a Department of Defense Robert L. Woods Award for "Leadership in the Vacuum Electronics Community." He is a member of Sigma Xi.

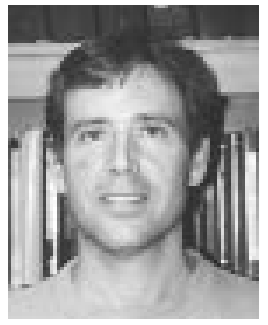

Wes G. Lawson (S'84-M'85-SM'97) received the B.S. degree in mathematics (1980) and the B.S. (1980), M.S. (1981), and Ph.D. (1985) degrees in electrical engineering from the University of Maryland. His dissertation work involved theoretical and experimental studies of microwave generation in various large-orbit gyrotron configurations.

Wes worked in the Electronic Systems Branch of Harry Diamond Laboratories from 1978 to 1982 . He has been with the University of Maryland's Laboratory for Plasma Research for the past 16 years and is currently a Professor in the Department of Electrical Engineering. His principle interest lies in novel fast-wave microwave sources and his recent efforts have been directed toward high power fast-wave and hybrid amplifiers and associated high power microwave components. 


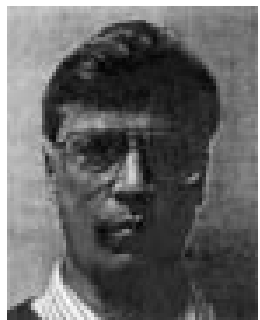

Thomas M. Antonsen, Jr. (M'87) was born in Hackensack, NJ in 1950. He received the Bachelor's degree in electrical engineering in 1973, and his Master's and Ph.D. degrees in 1976 and 1977, all from Cornell University. He was a National Research Council Post Doctoral Fellow at the Naval Research Laboratory in 1976-1977, and a Research Scientist in the Research Laboratory of Electronics at MIT from 1977 to 1980. In 1980, he moved to the University of Maryland where he joined the faculty of the departments of Electrical Engineering and Physics in 1984. He is currently a Professor of Physics and Electrical Engineering. He has held visiting appointments at the Institute for Theoretical Physics (U.C.S.B.), the Ecole Polytechnique Federale de Lausanne, Switzerland, and the Institute de Physique Theorique, Ecole Polytechnique, Palaiseau, France. He was selected as a Fellow of the Division of Plasma Physics of the American Physical Society in 1986.

Prof. Antonsen's research interests include the theory of magnetically confined plasmas, the theory and design of high power sources of coherent radiation, nonlinear dynamics in fluids, and the theory of the interaction of intense laser pulses and plasmas. He is the author and coauthor of more than 180 journal articles and coauthor of the book Principles of Free-electron Lasers. He has served on the editorial board of Physical Review Letters. The Physics of Fluids, and Comments on Plasma Physics. 